\title{
Preparation of a Frozen Regolith Simulant Bed for ISRU Component Testing in a Vacuum Chamber
}

Julie Kleinhenz and Diane Linne

Glenn Research Center, Cleveland, Ohio 


\section{NASA STI Program . . . in Profile}

Since its founding, NASA has been dedicated to the advancement of aeronautics and space science. The NASA Scientific and Technical Information (STI) program plays a key part in helping NASA maintain this important role.

The NASA STI Program operates under the auspices of the Agency Chief Information Officer. It collects, organizes, provides for archiving, and disseminates NASA's STI. The NASA STI program provides access to the NASA Aeronautics and Space Database and its public interface, the NASA Technical Reports Server, thus providing one of the largest collections of aeronautical and space science STI in the world. Results are published in both non-NASA channels and by NASA in the NASA STI Report Series, which includes the following report types:

- TECHNICAL PUBLICATION. Reports of completed research or a major significant phase of research that present the results of NASA programs and include extensive data or theoretical analysis. Includes compilations of significant scientific and technical data and information deemed to be of continuing reference value. NASA counterpart of peer-reviewed formal professional papers but has less stringent limitations on manuscript length and extent of graphic presentations.

- TECHNICAL MEMORANDUM. Scientific and technical findings that are preliminary or of specialized interest, e.g., quick release reports, working papers, and bibliographies that contain minimal annotation. Does not contain extensive analysis.

- CONTRACTOR REPORT. Scientific and technical findings by NASA-sponsored contractors and grantees.
- CONFERENCE PUBLICATION. Collected papers from scientific and technical conferences, symposia, seminars, or other meetings sponsored or cosponsored by NASA.

- SPECIAL PUBLICATION. Scientific, technical, or historical information from NASA programs, projects, and missions, often concerned with subjects having substantial public interest.

- TECHNICAL TRANSLATION. Englishlanguage translations of foreign scientific and technical material pertinent to NASA's mission.

Specialized services also include creating custom thesauri, building customized databases, organizing and publishing research results.

For more information about the NASA STI program, see the following:

- Access the NASA STI program home page at http://www.sti.nasa.gov

- E-mail your question to help@sti.nasa.gov

- Fax your question to the NASA STI Information Desk at 443-757-5803

- Phone the NASA STI Information Desk at 443-757-5802

- Write to: STI Information Desk NASA Center for AeroSpace Information 7115 Standard Drive Hanover, MD 21076-1320 


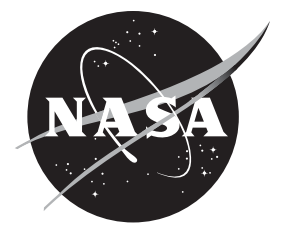

\section{Preparation of a Frozen Regolith Simulant Bed for ISRU Component Testing in a Vacuum Chamber}

Julie Kleinhenz and Diane Linne

Glenn Research Center, Cleveland, Ohio

Prepared for the

51st Aerospace Science Conference

sponsored by the American Institute of Aeronautics and Astronautics

Grapevine, Texas, January 7-19, 2013

National Aeronautics and

Space Administration

Glenn Research Center

Cleveland, Ohio 44135 


\section{Acknowledgments}

This work is supported by the Regolith and Environment Science and Oxygen and Lunar Volatile Extraction (RESOLVE) project under the Advanced Exploration Systems (AES) program and the ISRU Project under the Game Changing Technology Division of the Space Technology Program.

Level of Review: This material has been technically reviewed by technical management.

Available from

NASA Center for Aerospace Information 7115 Standard Drive

Hanover, MD 21076-1320
National Technical Information Service 5301 Shawnee Road Alexandria, VA 22312

Available electronically at http://www.sti.nasa.gov 


\title{
Preparation of a Frozen Regolith Simulant Bed for ISRU Component Testing in a Vacuum Chamber
}

\author{
Julie Kleinhenz and Diane Linne \\ National Aeronautics and Space Administration \\ Glenn Research Center \\ Cleveland, Ohio 44135
}

\begin{abstract}
In-Situ Resource Utilization (ISRU) systems and components have undergone extensive laboratory and field tests to expose hardware to relevant soil environments. The next step is to combine these soil environments with relevant pressure and temperature conditions. Previous testing has demonstrated how to incorporate large bins of unconsolidated lunar regolith into sufficiently sized vacuum chambers. In order to create appropriate depth dependent soil characteristics that are needed to test drilling operations for the lunar surface, the regolith simulant bed must by properly compacted and frozen. While small cryogenic simulant beds have been created for laboratory tests, this scale effort will allow testing of a full $1 \mathrm{~m}$ drill which has been developed for a potential lunar prospector mission. Compacted bulk densities were measured at various moisture contents for GRC-3 and Chenobi regolith simulants. Vibrational compaction methods were compared with the previously used hammer compaction, or "Proctor", method. All testing was done per ASTM standard methods. A full $6.13 \mathrm{~m}^{3}$ simulant bed with 6 percent moisture by weight was prepared, compacted in layers, and frozen in a commercial freezer. Temperature and desiccation data was collected to determine logistics for preparation and transport of the simulant bed for thermal vacuum testing. Once in the vacuum facility, the simulant bed will be cryogenically frozen with liquid nitrogen. These cryogenic vacuum tests are underway, but results will not be included in this manuscript.
\end{abstract}

\section{Nomenclature}

$\begin{array}{ll}\text { ASTM } & \text { American Society for Testing and Materials } \\ \text { ISRU } & \text { In-Situ Resource Utilization } \\ \text { LCROSS } & \text { Lunar Crater Observation and Sensing Satellite } \\ \text { LRO } & \text { Lunar Reconnaissance Orbiter } \\ \text { RESOLVE } & \text { Regolith and Environment Science, Oxygen and Lunar Volatiles Extraction } \\ \text { VF } & \text { Vacuum Facility }\end{array}$

\section{Introduction}

Exploration of extraterrestrial environments will require rugged hardware that can withstand a variety of unique environmental conditions. These environments include extreme pressure and temperature conditions, but for In-Situ Resource Utilization (ISRU) this also includes heavy exposure to surface material, or regolith. ISRU systems can consist of drills, excavators, reactors, and sensitive science equipment that must withstand direct interaction with the abrasive regolith. Earth-based testing of hardware in relevant environments is key to understanding these interactions and developing appropriate hardware.

The Regolith and Environment Science, Oxygen and Lunar Volatiles Extraction (RESOLVE) project is a prospective ISRU mission that will prospect for volatile resources in the cold regions near the lunar poles. Potential instruments included in the RESOLVE payload are a coring drill and auger designed to obtain samples down to $1 \mathrm{~m}$ depth. The project has undergone several hardware iterations including breadboard and field demonstrations. These tests examined operational and integration methods using 
various lunar regolith simulants. RESOLVE is now preparing for environmental testing in a lunarrelevant thermal vacuum environment, which must necessarily include lunar regolith simulant.

When exposed to vacuum, gas trapped in and adsorbed onto earth-based granular media (such as lunar regolith simulant) is released. This gas release can occur violently, which loosens and weakens the simulant, altering the consolidation state. Previous studies (Ref. 1) using a 1-ton bin of lunar regolith simulant LHT-3M in a vacuum chamber have identified operational procedures to avoid this violent gas release and maintain the soil state. This study is the largest simulant bin tested in a vacuum chamber to date, and serves as the spring-board for future component and hardware systems tests.

Testing of the RESOLVE drill and auger requires a simulant bed prepared to a controlled moisture content and density to mimic expected, and worst-case, lunar surface conditions for the drill subsystem. The prepared simulant bed will also be cryogenically frozen using liquid nitrogen within the vacuum chamber. These tests will be performed in the same vacuum chamber and with the same procedural techniques as Ref. 1. However, the size of the simulant bin will be altered to better accommodate the hardware and facilitate freezing. Instead of the 1- by 1 - by $0.7-\mathrm{m}$ (depth) square bin from Reference 1, a $0.278 \mathrm{~m}$ diameter, $1.2 \mathrm{~m}$ tall cylindrical bin will be used.

In preparation for the RESOLVE vacuum component testing, simulant bed preparation and initial vacuum tests are underway. This document describes procedures for the soil preparation up to the point of vacuum testing.

\section{Objectives}

The first critical objective for the simulant bed preparation was to find a way to compact the soil to obtain a repeatable bulk densities that are representative of the lunar regolith. While returned core sample density measurements from the Luna and Apollo missions ranged from 1.1 to $2.3 \mathrm{~g} / \mathrm{cm}^{3}$, the most common values were in the range of the 1.5 to $1.9 \mathrm{~g} / \mathrm{cm}^{3}$ (see Ref. 2, table 9.4). Prior to flight it is desirable to test the hardware at conditions that meet or exceed the most challenging conditions expected on the Moon to ensure mission success. Therefore, one objective was to compact to maximum density. However, lower densities might also present a challenge in maintaining and transferring core samples and should also be tested prior to flight.

Smaller scale drill tests (Ref. 3) utilized the ASTM D698 "Proctor" compaction method, (Ref. 4) in which a weight is repeatedly dropped on the surface of the material. According to the ASTM standard, this method accommodates a soil bed $11.4 \mathrm{~cm}$ (4.5 in.) deep, $15.2 \mathrm{~cm}$ (6 in.) in diameter and requires 56 drops of the $2.5 \mathrm{~kg}$ rammer weight from a height of $12 \mathrm{in}$. When considering a layered fill of a $1 \mathrm{~m}$ tall simulant bed, and performing this procedure on each layer, this is a time consuming prospect. The moist simulant would also be exposed to room air during the compaction process, giving it the opportunity to desiccate. A more timely way of soil compaction is the vibration method described in ASTM D4253 (Ref. 5). In this method, a surcharge weight $\left(2 \mathrm{lb} / \mathrm{in}^{2}\right)$ is placed on the surface of the soil while the entire soil bed is vibrated. The vibration compaction standard also specifies a soil depth of $20.3 \mathrm{~cm}(8 \mathrm{in})$ with a $27.9 \mathrm{~cm}$ (11 in) diameter. This larger diameter is better suited to the drill/auger tests since multiple drill holes are feasible within the simulant bed. Considering the preparation time of the simulant and the time needed to achieve desired vacuum conditions (up to a week based on Ref. 1), the possibility of multiple drill points was highly desired. However, a layered compaction would still be required to achieve the appropriate simulant bed depth, and it had to be demonstrated that the vibration would not disturb previously compacted layers.

The second objective in the simulant bed preparation was to add a known amount of moisture to the simulant. Based on LCROSS and LRO data (Ref. 6), the moisture content in the near permanently shadowed regions of the moon is expected to be around 5 percent by mass. To challenge the drill hardware, the simulant bed should be at its maximum bulk density at each moisture condition. Baseline tests were performed with the ASTM vibration method to determine the moisture-dependent bulk densities. Compaction tests were done with lunar regolith simulants GRC-3 and Chenobi. The GRC-3 
was used for initial tests to determine procedures, since it is less expensive and more available. The RESOLVE drill hardware tests will use Chenobi.

The final simulant bed preparation objective is to study how to cryogenically freeze the simulant bed in a vacuum chamber. This involves monitoring the temperature and pressure profile to determine the time scales and temperature uniformity. The condition of the simulant bed will also be examined during and after the pump down for evidence of gas release effects. Moisture content will also be examined at the end of the test to look for desiccation.

\section{Equipment and Facilities}

All simulant handling and preparation work was performed in the Simulated Lunar OPErations (SLOPE) laboratory at NASA Glenn Research Center. The primary feature of the SLOPE lab is the mobility and traction test bed with an adjustable tilt angle up to $45^{\circ}$. Since the lab has safety features to allow safe handling of large quantities of lunar regolith simulants, it is also used for soil preparation and soil mechanics tests. A variety of equipment is available for this purpose. For the current test program this equipment included an oven, a cement mixer, a vibration table, and a commercial upright freezer (Figure 1). The oven was used for desiccating the simulant. It can accommodate three baking trays of simulant, each of which can hold $1.5 \mathrm{~kg}$ of simulant. The cement mixer was used for moisture addition. Water was added as the simulant was mixed to ensure uniform distribution. The vibration table, used for compaction, has a fixed vibration frequency of $60 \mathrm{~Hz}$ and adjustable amplitude, which meets the requirements of the ASTM D4253 for compaction (Ref. 5). Finally, the upright freezer was used to chill the simulant prior to transport to the vacuum chamber facility where it will be cryogenically cooled. This initial freeze solidified the soil state to prevent disturbance of the simulant bed during transport. The freezer can maintain a temperature of $-20^{\circ} \mathrm{C}$.

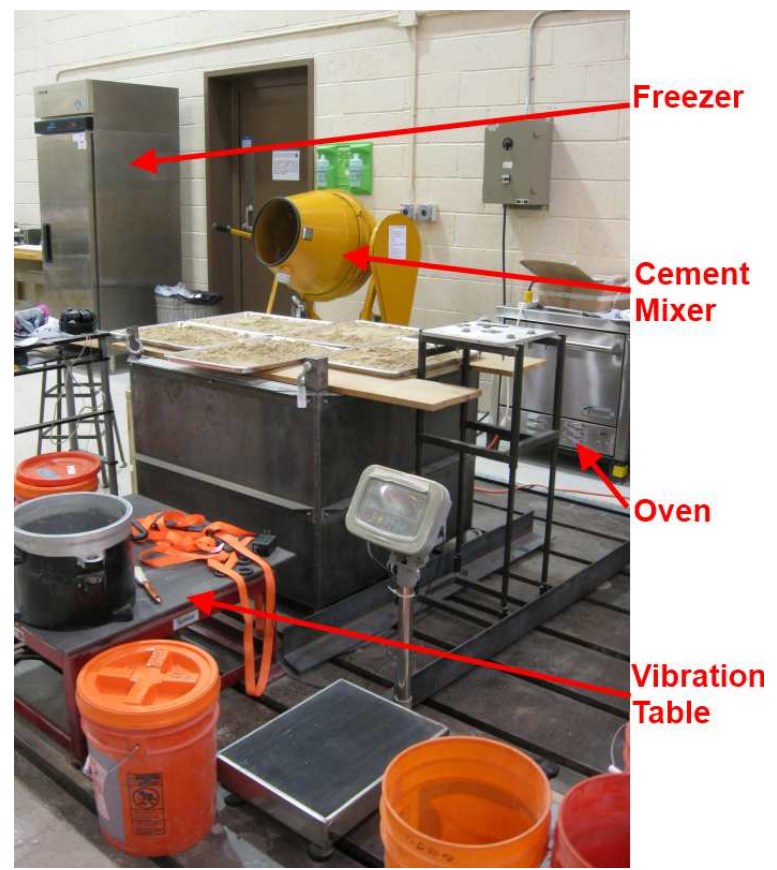

Figure 1.-Simulant preparation equipment in the SLOPE lab. 

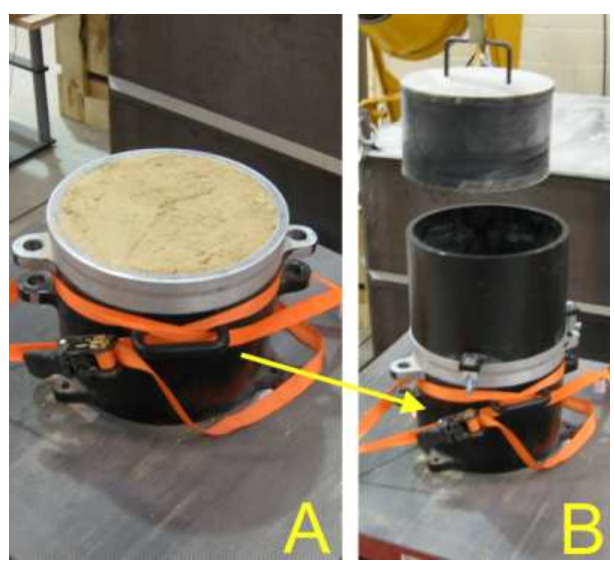

Figure 2.-The apparatus for the ASTM D4253 vibration compaction tests. A) The $0.5 \mathrm{ft}^{3}$ mold filled with GRC3 simulant. B) The guide sleeve is attached to the top of the mold, and the weight is lowered.

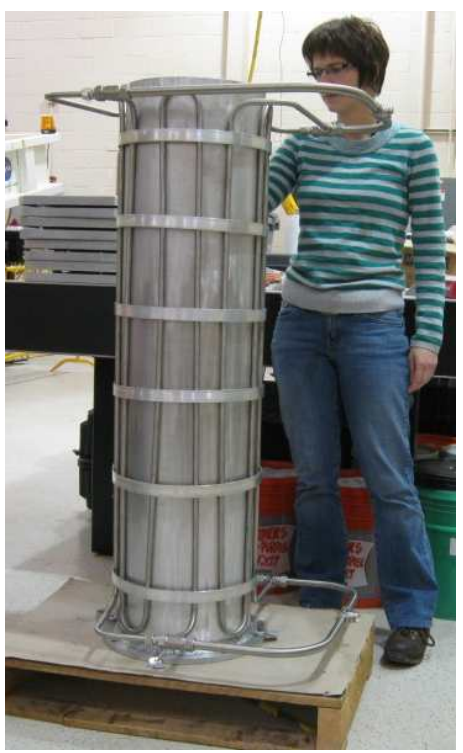

Figure 3.-The cylindrical simulant bin shown with the coolant loops clamped on.

The baseline compaction tests were performed in the apparatus in Figure 2 which was designed according to ASTM vibration standard D4253 (Ref. 4). This $14200 \mathrm{~cm}^{3}\left(0.5 \mathrm{ft}^{3}\right)$ mold (Figure 2A) has an internal diameter of $27.94 \mathrm{~cm}$ (11in). A baseplate (not shown) sits atop the simulant and supports the $79.4 \mathrm{~kg}(175 \mathrm{lb})$ surcharge weight. A guide sleeve is attached to the top of the mold to contain the surcharge weight during vibration (Figure 2B). The assembly is then strapped securely to a $60 \mathrm{~Hz}$ vibration table and vibrated. This apparatus was used to map the maximum bulk densities of the simulants at the different moisture contents. These densities were then used to develop the compaction procedures for the taller cylindrical bin.

The simulant bed for the vacuum chamber tests was a $1.2 \mathrm{~m}$ (48 in.) cylinder (Figure 3). The inner diameter was $0.278 \mathrm{~m}$ (11 in.), which is identical to the ASTM apparatus so that procedures and equipment (surcharge weight, baseplate) from the smaller ASTM apparatus could be used. Three feedthrough ports at various heights along the drill tube accommodated thermocouple probes. Each probe had five type $T$ thermocouples which were embedded in the soil at different radial positions, as shown in Figure 4 . These probes were embedded as the bin was filled with simulant, and the simulant was compacted on top of them.

The vacuum facility that will be used, VF-13, is a vertical, cylindrical chamber with an internal volume of $6.35 \mathrm{~m}^{3}$ (Figure 5). The bulk of the volume is within the removable $2.52 \mathrm{~m}$ tall by $1.5 \mathrm{~m}$ diameter lid (the white portion in Figure 5). The fixed base is $1.08 \mathrm{~m}$ deep and accommodates all the electrical, mechanical, and gas feed-throughs. Four different types of pumps can be used to achieve a pressure of $10^{-6}$ Torr. Liquid nitrogen is plumbed to the facility to accomplish cryogenic cooling of the simulant bin. Coolant loops (Figure 3) are clamped to the bin and the simulant bed is chilled as a vacuum is pulled. A cryogenic shroud (liquid nitrogen) will be available in the lid portion of VF13 during RESOLVE component testing. 

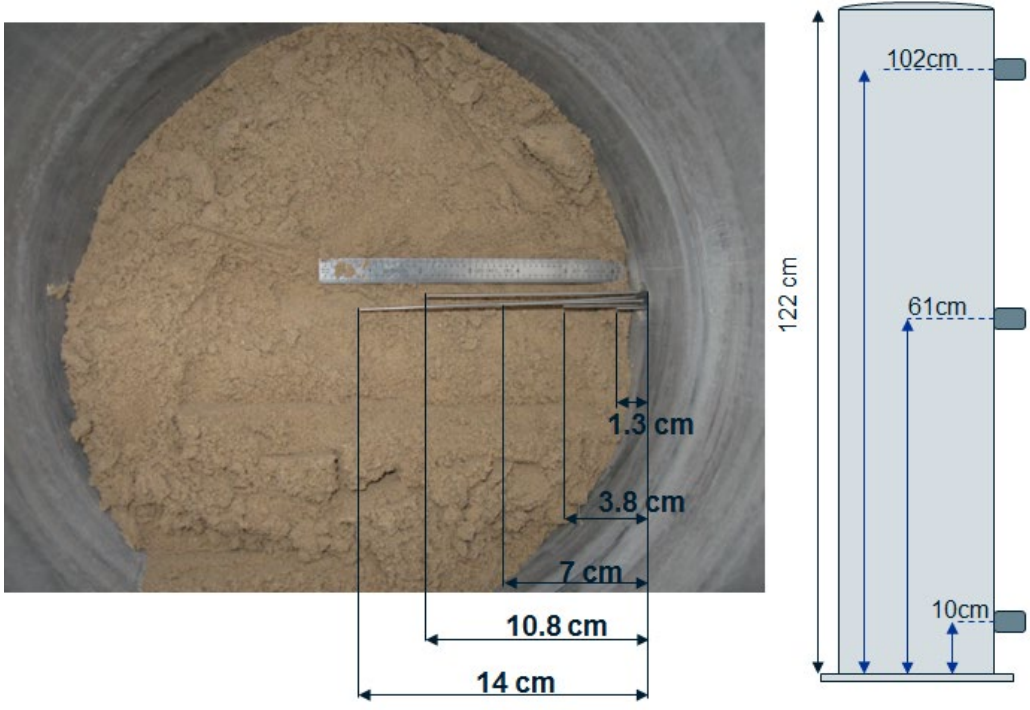

Figure 4.-The position of the thermocouples in the simulant bed. At left, the radial positions of the thermocouple rake. At right, the axial position of each thermocouple rake.

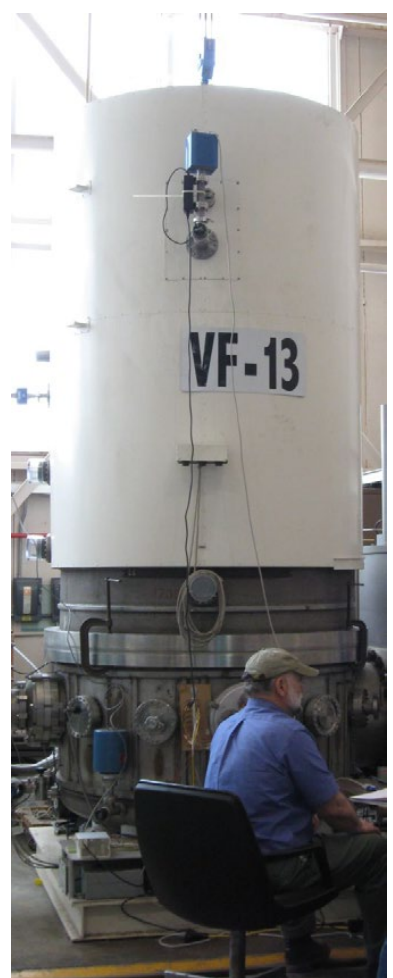

Figure 5.-The VF13 vacuum facility, shown sealed.

\section{Results and Discussion}

The following sections describe the different aspects of soil preparation. In the case of moisture addition and compaction, these are methods to scale-up the procedures set forth in the ASTM standards. Simulant specific data for GRC-3 and Chenobi simulants include bulk densities versus moisture content. Rudimentary data regarding time dependent desiccation and moisture absorption in room conditions helped determine logistics for simulant handling. Moist simulant was frozen in a commercial freezer, and then thawed, to determine temperature uniformity over time. Simulant preparation up to the point of vacuum testing will be covered. Thermal vacuum data is left for a later publication.

\section{Simulant Moisture Addition}

One of the goals of the RESOLVE project is to determine the volatile water content of the lunar regolith (water ice, or loosely bound). Validation testing must therefore address a range of possible moisture contents that may exist on the lunar surface. The cylindrical bin holds over $150 \mathrm{~kg}$ of lunar regolith simulant, so procedures were developed to prepare a large quantity of simulant to a known moisture state. This involved adding, and uniformly distributing, a known amount of water into the simulant. To do so, it was also important to understand the moisture content of the simulant at room conditions and how quickly the moist simulant would desiccate when exposed to room conditions. As mentioned, two types of lunar soil simulant were used. GRC-3 is a lower cost, lower fidelity physical simulant that was used for check out tests. Chenobi simulant is a higher fidelity lunar highlands simulant that will ultimately be used for RESOLVE drill hardware tests. Moisture tests were performed on both.

To determine the water content of the simulant, small samples $(\sim 40 \mathrm{~g})$ were baked in an oven as per ASTM D2216 (Ref. 7). The samples were baked at $100 \pm 5^{\circ} \mathrm{C}$ overnight, though mass loss typically 
stopped after $4 \mathrm{hr}$. The samples were weighed before and after oven exposure and were kept sealed when outside of the oven. At laboratory room conditions (typically 20 percent relative humidity) the GRC-3 simulant held approximately 0.5 percent moisture while the Chenobi held less than 0.1 percent. Dry samples were then allowed to reabsorb moisture, and regained 0.1 percent within $30 \mathrm{~min}$.

Increasing the moisture content of the simulant was done on a mass basis. Simulant was mixed in batches of 20 to $25 \mathrm{~kg}$, or a single 5 gal bucket. The mass of water to be added for a desired mass fraction was determined by Equation (1) where $m_{s}$ is the total simulant mass, $f_{w}$ is the water fraction desired, and $m_{w}$ is the mass of water added. Tap water was used for the GRC-3 test while distilled water was used with the Chenobi.

$$
m_{w}=\frac{\left(f_{w} m_{s}\right)}{\left(1-f_{w}\right)}
$$

A hand pump sprayer was used to spray the water into the cement mixer as simulant was added. This method achieved a uniform distribution of the water without the simulant 'clumping'. Once mixing was complete the moist simulant was allowed to cure in a sealed bucket overnight (as per Ref. 4). To verify the water content, two $40 \mathrm{~g}$ samples from each soil bucket were baked out using the procedures described above. Moisture contents were generally within 1 percent of the target when the simulant was not oven dried prior to moisture addition. One would expect that without drying, the moisture contents would be consistently higher than the target, but from Table 1, that is not the case. Even multiple samples from the same simulant batch had as much as 0.5 percent (average 0.3 percent) variation moisture content. Other sources of error that could cause moisture variations include attrition of water and simulant during mixing, resolution of the scale $(0.01 \mathrm{~kg})$, and desiccation. When choosing moisture conditions for RESOLVE validation testing, a resolution of 1 percent should be used.

TABLE 1.-THE TARGET WATER CONTENT IS SHOWN WITH THE ACTUAL WATER CONTENT, AS MEASURED BY ASTM D2216

\begin{tabular}{|l|c|c|c|}
\hline \multicolumn{1}{|c|}{ Test designation } & $\begin{array}{c}\text { Target } \\
\text { water }\end{array}$ & $\begin{array}{c}\text { Measured } \\
\text { water }\end{array}$ & $\begin{array}{c}\text { Deviation } \\
\text { from target }\end{array}$ \\
\hline GRC-3 room.1 & -------- & 0.42 & ------- \\
\hline GRC-3 6.1 & 6.00 & 5.84 & -0.16 \\
& 6.00 & 5.72 & -0.28 \\
\hline GRC-3 6.2 & 6.00 & 6.34 & 0.34 \\
\hline GRC-3, 8.1 & 8.00 & 9.39 & 1.39 \\
& 8.00 & 9.79 & 1.79 \\
\hline \multirow{2}{*}{ GRC-3 11.1 } & 11.00 & 11.90 & 0.90 \\
& 11.00 & 11.59 & 0.59 \\
\hline Chenobi room.1 & ------- & 0.05 & ------- \\
\hline Chenobi room.2 & -------- & 0.05 & -------- \\
\hline Chenobi, 2.1 & 2.00 & 2.02 & 0.02 \\
*oven dry & 2.00 & 1.78 & -0.22 \\
\hline \multirow{2}{*}{ Chenobi 5.1 } & 5.00 & 4.74 & -0.26 \\
\hline \multirow{2}{*}{ Chenobi 8.1 } & 5.00 & 4.54 & -0.46 \\
\hline \multirow{2}{*}{ Chenobi 10.1 } & 8.00 & 8.68 & 0.68 \\
& 8.00 & 8.81 & 0.81 \\
\hline & 10.00 & 10.54 & 0.54 \\
& 10.00 & 11.08 & 1.08 \\
\hline
\end{tabular}




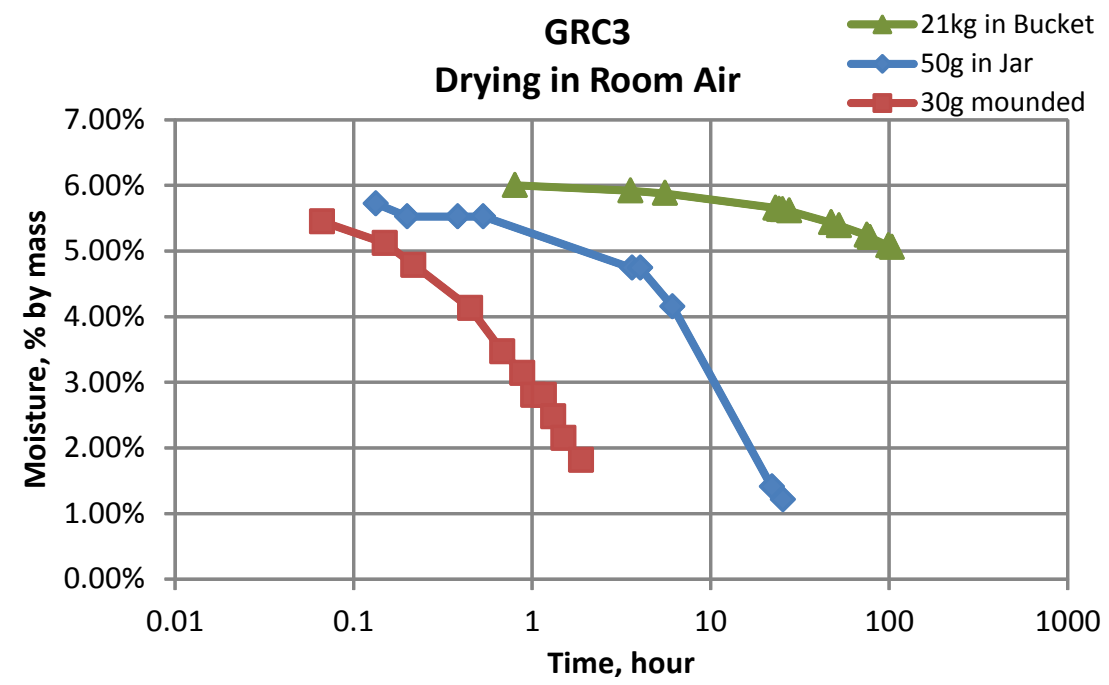

Figure 6.-Desiccation of GRC-3 in room air.

Figure 6 is an indication of how quickly the simulant desiccates when exposed to room conditions. This data gives an idea of how long GRC-3 simulant may be handled in room conditions during compaction, transfer, etc. Three different configurations are shown; $21 \mathrm{~kg}$ of simulant in a 5 gal bucket ( $30 \mathrm{~cm}$ diameter at the soil surface), a $50 \mathrm{~g}$ sample in a $3 \mathrm{~cm}$ tall by $5 \mathrm{~cm}$ diameter jar ( $8 \mathrm{oz}$ ), and $30 \mathrm{~g}$ of simulant in a fully exposed pile. All samples start at $\sim 6$ percent water by mass. The relative humidity of the room was typically 20 percent. The jar, in which only the surface is exposed, reduces by 1 percent within the first $5 \mathrm{hr}$, while the mounded simulant only takes $15 \mathrm{~min}$ due to the increased surface area. The simulant is generally prepared in batches of 20 to $25 \mathrm{~kg}$, so the $21 \mathrm{~kg}$ test shown here is the most relevant to test logistics. It takes nearly three days for the bucket to lose 1 percent of its moisture. While the simulant on the surface of the bucket visibly dries with a few hours, the soil beneath the surface is damp. Generally compaction procedures with a simulant batch take 1 to $2 \mathrm{hr}$. Based on the results shown in Figure 6, this amount of time should not represent a significant desiccation.

When dry samples were desired, the simulant was placed on baking sheet trays, which could hold about $1.5 \mathrm{~kg}$ simulant each. Three trays could be baked simultaneously in the oven at $110^{\circ} \mathrm{C}$. With the high surface area, the samples dried (no further mass loss) within $30 \mathrm{~min}$.

\section{Simulant Compacted Densities}

Once the simulant was prepared to the desired moisture content, it was compacted to achieve a maximum bulk density. These compactions were done with procedures and apparatus listed in ASTM D4253 for vibrational compaction (Ref. 5). The $14200 \mathrm{~cm}^{3}\left(0.5 \mathrm{ft}^{3}\right)$ mold was filled with the simulant and the $79.4 \mathrm{~kg}(175 \mathrm{lb})$ surcharge weight was placed on the surface. The apparatus was then strapped securely to the vibration table. For tests with added moisture, the mold was filled with simulant as it was vibrated at a low level. This was not done with dry simulant since the airborne particulate would have created a hazard. As per the standard, the simulant was vibrated for $8 \mathrm{~min}$ at $60 \mathrm{~Hz}$. The amplitude of the vibration was controlled via a rheostat. The standard specifies an acceleration of $14 \mathrm{~m} / \mathrm{s}^{2}(1.5 \mathrm{~g})$ to $45 \mathrm{~m} / \mathrm{s}^{2}(4.8 \mathrm{~g})$. An accelerometer was used in several tests to determine the necessary rheostat setting to achieve this. Generally, a setting of 12 percent resulted in an acceleration of 20 to $24 \mathrm{~m} / \mathrm{s}^{2}$ and resulted in the best compaction. The sound of the vibration was generally a good indicator of appropriate rheostat setting. As the rheostat was increased to 12 percent, the sound would go from a low level 'buzz' to a loud rumble. At this transition point the surcharge weight visibly rotated and bounced slightly. The change in height of soil bed was also measured at 1 min intervals during vibration. To achieve the best results, the rheostat was set at 12 percent for the first 5 min of vibration. At this point, simulant height had stabilized. 


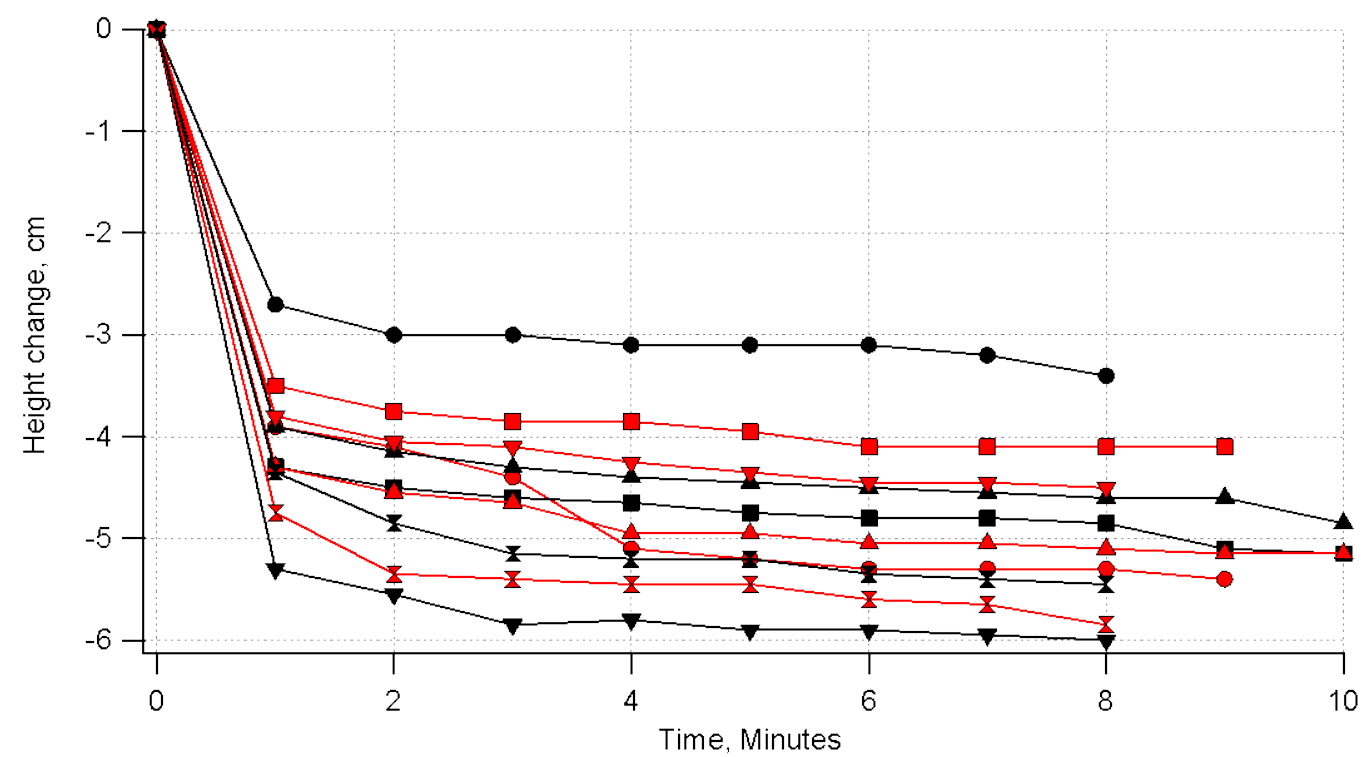

Figure 7.-Compaction as a function of vibration time. A range of test conditions are shown, lines link points from a single test condition.

By ramping the rheostat between 0 and 40 percent for the remaining $3 \mathrm{~min}$ an additional few millimeters of compaction could be achieved. Figure 7 shows bed height measurements during vibration with an accuracy of $\pm 2 \mathrm{~mm}$. (The last data point was always taken after vibration stopped, which explains the additional few millimeters of compaction). The majority of the compaction occurs with in the first $2 \mathrm{~min}$ of vibration, with only a few millimeters change after. This result agrees with Reference 8 . However, the full 8 min vibration was performed for traceability to the ASTM standard and to ensure the last few millimeters of compaction could be achieved. The simulant mass was measured after vibration and after the surcharge weight and baseplate were removed from the simulant surface. The density was then determined using this mass and the final simulant height within the mold.

The resulting wet densities are shown in Figure 8. For the GRC-3 simulant, several repeat tests were conducted at water fractions below 6 percent, which are most expected in the lunar regolith. These tests demonstrated that densities were very repeatable using the vibration compaction method. For both the GRC-3 and Chenobi, the compacted bulk density initially decreases as water is added to the simulant. This was also seen in other simulants like JSC-1A (Ref. 10) and LHT-2M (Ref. 11).

Results from previous studies (Ref. 9) ${ }^{1}$ that used the Proctor compaction method (ASTM D698) are also plotted in Figure 8. Note that the goal of these previous tests, and the goal of the ASTM standard D698, was to determine the moisture content that produced the maximum dry bulk density. Thus, results from these Proctor method studies were reported as equivalent dry bulk density and were converted to wet bulk densities using Equation (2) where $\rho$ is density and $f_{\text {water }}$ is the water fraction of the simulant by mass.

$$
\rho_{\text {dry }}=\frac{\rho_{\text {wet }}}{1+f_{\text {water }}}
$$

All densities in Figure 8 are wet densities $\left(\rho_{\text {wet }}\right)$. In the present work, the goal was to find the maximum bulk density at moisture contents in the range of 0 to 8 percent water by mass. However, the Proctor method tests typically miss the dip in bulk density at these lower moisture contents based on the advice in

\footnotetext{
${ }^{1}$ The data for Chenobi compaction tests using Proctor method were obtained from NORCAT (NOrthern Center for Advanced Technologies) via personal communication.
} 


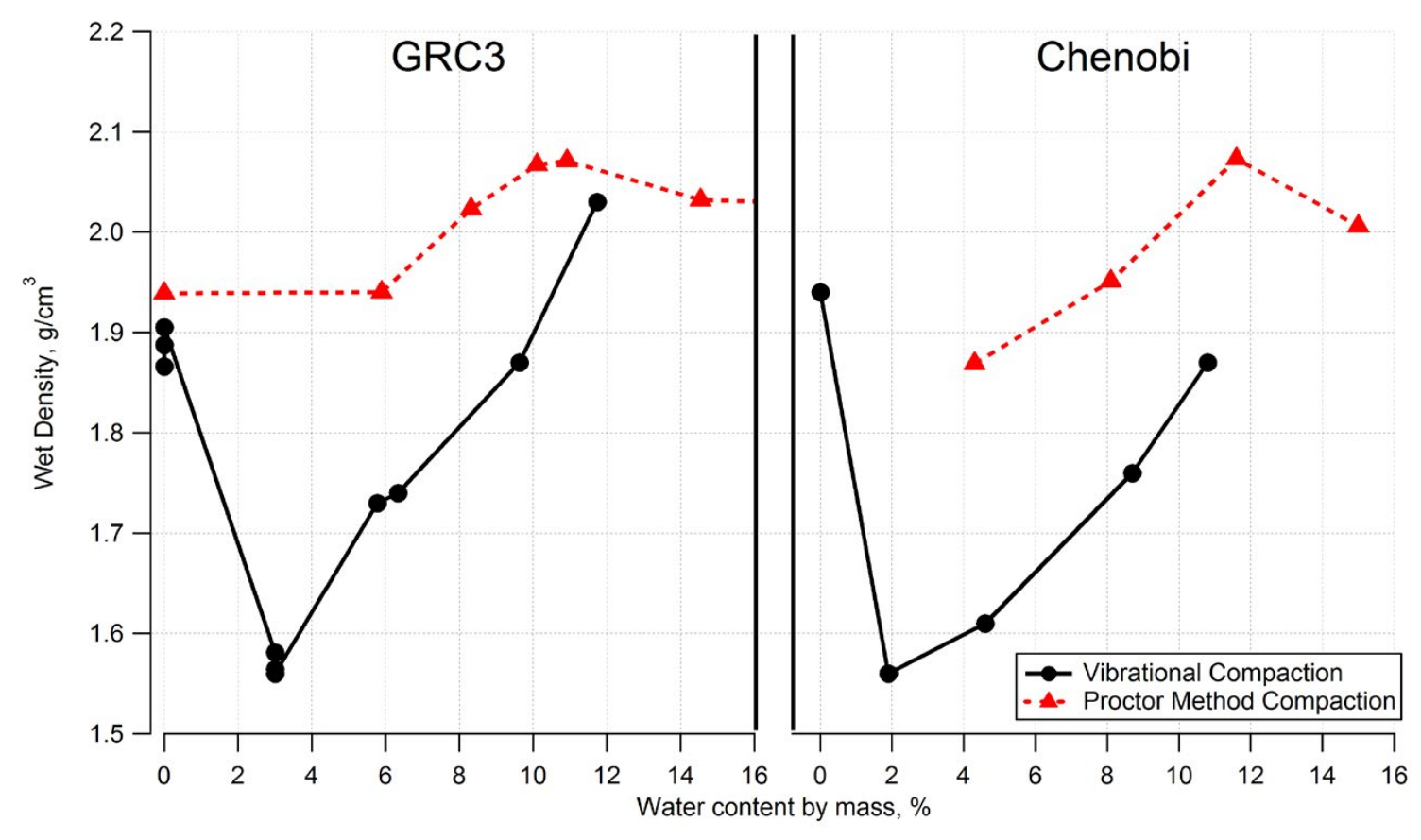

Figure 8.-Wet compacted densities for GRC-3 and Chenobi simulants at different moisture contents.

ASTM D698 (Ref. 4), "Typically soils at the optimum water content can be squeezed into a lump that sticks together when hand pressure is released..." The optimum water content in this context refers to the maximum dry bulk density. Simulant of this consistency tends to happen at water contents greater than 5 percent. While higher densities were achieved in the previous studies, the Proctor method is not necessarily superior for this situation. The Proctor method specifies a diameter smaller than what was required for the simulant bed, and it is unknown how effective the method would be with a larger diameter bed. Given that the densities obtained using the vibration method were within the range of the lunar surface measurements (Ref. 2), and that the logistics are better suited to the simulant bed preparation, the vibration results were a good match to the objectives of the RESOLVE project.

\section{Simulant Test Bed Preparation}

The next step was to determine if the bulk densities determined in the ASTM mold could be achieved in the larger cylindrical bin. Since the height of the simulant bed would be five times greater than that of the ASTM apparatus, the effectiveness of vibration may be different. The simulant for the cylindrical bin tests was prepared in batches of $\sim 25 \mathrm{~kg}$ ( 5 gal buckets). A layered fill was then performed whereby the bin underwent vibration compaction after each successive layer. The compaction procedures established with the smaller ASTM apparatus were used. With the additional mass of the bin, vibration was adjusted with a higher rheostat setting. This setting was gauged by the sound and visible motion of the surcharge weight, as observed in the ASTM apparatus tests. The bin was also strapped securely to the vibration table during each compaction, as was done in the ASTM tests. The bulk density of the total simulant bed was measured after each layer was added (the bulk density listed for layer 2 includes layers 1 and 2, and layer 5 is the bulk density of all the layers combined). The results of two of these tests are shown in Table 2. In the first test, GRC-3 at room 'dry' conditions (no moisture added) was used. The bulk density after each layer was very consistent for all but the last (top) layer. A larger mass of soil was added in this final layer to top off the bin and resulted in a less effective compaction. 
TABLE 2.-THE BULK DENSITIES DURING LAYERED FILL AND COMPACTION

OF THE SIMULANT BED. LAYER 5 REPRESENTS A FILLED BED

\begin{tabular}{|c|c|c|c|c|c|}
\hline \multirow{2}{*}{ Layer } & \multicolumn{2}{|c|}{ GRC-3 room dry } & \multicolumn{3}{c|}{ GRC-3 6 moisture } \\
\cline { 2 - 6 } & $\begin{array}{c}\text { Layer mass, } \\
\mathrm{kg}\end{array}$ & $\begin{array}{c}\text { Compacted density, } \\
\mathrm{g} / \mathrm{cm}^{3}\end{array}$ & $\begin{array}{c}\text { Layer mass, } \\
\mathrm{kg}\end{array}$ & $\begin{array}{c}\text { Compacted density, } \\
\mathrm{g} / \mathrm{cm}^{3}\end{array}$ & $\begin{array}{c}\text { Moisture content, } \\
\%\end{array}$ \\
\hline 1 & 25.7 & 1.85 & 24.4 & 1.59 & 5.72 \\
2 & 24.5 & 1.85 & 25.0 & 1.57 & 6.21 \\
3 & 25.3 & 1.85 & 21.4 & 1.58 & 6.13 \\
4 & 20.8 & 1.85 & 21.2 & 1.57 & 6.31 \\
5 & 32.5 & 1.83 & 17.3 & 1.57 & 6.64 \\
\hline
\end{tabular}

For the next test, GRC-3 with 6 percent moisture content, all layers were $25 \mathrm{~kg}$ or less. While the first layer achieved a slightly higher compaction, the bulk density with subsequent layers was constant. This consistency suggests that the vibration was not altering the state of the previously compacted (lower) layers. However, all of these densities were lower than those achieved in the earlier ASTM tests (Figure 8). Given that the cross section area, surcharge weight, etc. matched those of the smaller apparatus, it is surprising that at least the first layer did not match the ASTM results. Additional tests have not yet been performed to resolve this, but one difference was the fill method of the simulant. The cylindrical bin could not be vibrated during fill like the ASTM apparatus. Also, the layering in the bin was done on a mass basis whereas the ASTM apparatus was done by volume (e.g. the mold was entirely filled for each test). A higher mass, or deeper simulant layer, could have decreased the effectiveness of the vibration. For comparison, a single compaction was attempted with a single $116 \mathrm{~kg}$ room-dry simulant bed. The resulting bulk density for this room condition GRC-3 simulant was $1.74 \mathrm{~g} / \mathrm{cm}^{3}$, considerably less than the layered compaction test.

Another difference with the 6 percent moisture test was the addition of thermocouples in the simulant. These were used to monitor the thermal profile of the simulant during the subsequent freezing process. These thermocouple probes were embedded in the simulant during the fill process. Simulant was added until the level reached the feed through port. The thermocouple probe was then inserted (see Figure 4), the rest of the simulant layer was added, and then compacted. It was expected that the probes would be bent to some degree while the simulant was compacted atop them.

The filled bin was then inserted into a commercial upright freezer for an initial freeze prior to full cryogenic exposure. The vacuum facility with the cryogenic cooling capability is housed separate from the soils laboratory. Thus, freezing the simulant bed prior to transport would help solidify the soil state, maintaining the prepared density and preventing spills or material loss. The initial freeze would also reduce the degree of thermal shock that may occur when exposed to the liquid nitrogen. Temperatures were monitored during freezing, and then thawing to determine the logistics of the transport. The data acquisition system was configured to monitor 8 of the 15 thermocouples. The results of the freeze and thaw tests are shown in Figure 9, along with graphic to identify which thermocouples were monitored. As expected, the temperature rate leveled at $0{ }^{\circ} \mathrm{C}$ while the phase change occurred. The simulant nearest the wall (position 5) froze in $3 \mathrm{hr}$, and by $8 \mathrm{hr}$ the most insulated position, B1, was frozen. After $18 \mathrm{hr}$ the full simulant bed had reached equilibrium with the freezer temperature, $-20^{\circ} \mathrm{C}$. When exposed to room conditions $\left(22^{\circ} \mathrm{C}\right)$, the thaw process followed a similar timeline. The simulant nearest the wall thawed in $2 \mathrm{hr}$ while the full simulant bed (gauged by B1) thawed within $8 \mathrm{hr}$. The simulant at the bottom of the bed (probe A) was the most sensitive to temperature change. This sensitivity is likely due to the large thermal mass of the bottom flange, which has a higher thermal conductivity than the simulant. Note that the simulant bin was entirely uninsulated during these tests as a worst-case. 

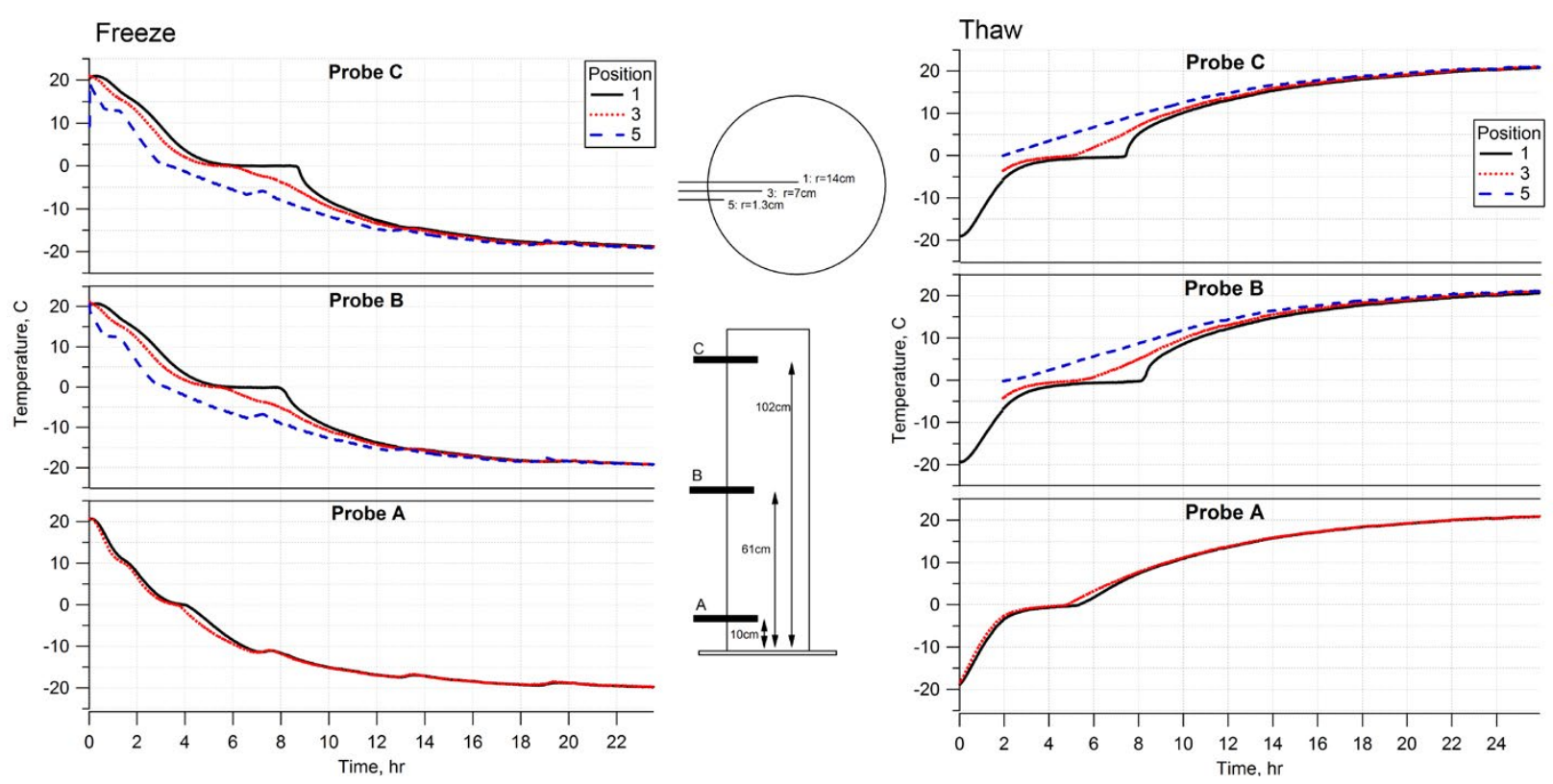

Figure 9.-The temperature traces of the filled simulant bed during freezing (left) and thaw (right). Eight thermocouple traces are shown, with positions indicated by the graphic.

Desiccation of the simulant bed in the freezer was also examined. While surface desiccation of the simulant bed would mimic lunar surface conditions, a uniform moisture profile would be more challenging to the drill hardware. In the upright freezer, a plug lid was inserted into the top of the bin and sealed using foam weather-stripping tape. This lid is not intended for the cryogenic freezing in the vacuum facility since there would be no way to remove it at vacuum. After the bin was removed from the freezer, a sample of the frozen simulant was chipped from the surface. The moisture content of this sample was 3 percent. With the lid in place, the simulant bed was allowed to thaw. Once it reached room temperature, another sample was removed from the surface. This had a moisture content of 5.9 percent. This indicates that the sample surface had desiccated in the freezer, but that the moisture was still trapped within the bin. Ice crystals were observed along the inner surface of the bin and on the bottom of the lid. A 3 percent moisture loss in the top $1 \mathrm{~cm}$ of the simulant translates to $29 \mathrm{ml}$ of water, which qualitatively is reasonable for the condensation observed. The thaw process took $24 \mathrm{hr}$, during which time at least some of this condensate would return to the simulant bed. The moisture in depth of the simulant bed would also have an opportunity to diffuse into the drier surface. Recall that the procedures for moisture addition described earlier include a cure period for this reason.

To illustrate this reabsorption process, a test was done with the air desiccated bucket discussed earlier (Figure 6). At the end of the desiccation test the bucket of soil had a moisture content of 5 percent with a visibly dry surface. A core sample was removed from the bucket using a $10 \mathrm{~cm}$ long scoop. The simulant was divided up into four sections to fill $8 \mathrm{oz}$ jars and then baked out to determine moisture. The bucket was then sealed and allowed to cure for 2.5 days. The same core sample method was used to collect depth samples. Table 3 shows the results. Even with a dry lid (no condensation dripping back into the sample) some moisture diffused into the surface. 
TABLE 3.-DEPTH DEPENDENT MOISTURE MEASUREMENTS

TAKEN AFTER DESICCATION IN ROOM CONDITIONS AND SUBSEQUENT 2.5 DAY SEALED CURE

\begin{tabular}{|l|c|c|}
\hline $\begin{array}{c}\text { Depth beneath } \\
\text { surface, } \\
\mathrm{cm}\end{array}$ & $\begin{array}{c}\text { After room desiccation, } \\
\%\end{array}$ & $\begin{array}{c}\text { After cure 2.5 day, } \\
\%\end{array}$ \\
\hline 0 , surface & 0.6 & 1.9 \\
4 to 7 & 5.0 & 4.7 \\
7 to 10 & 5.1 & 5.2 \\
\hline
\end{tabular}

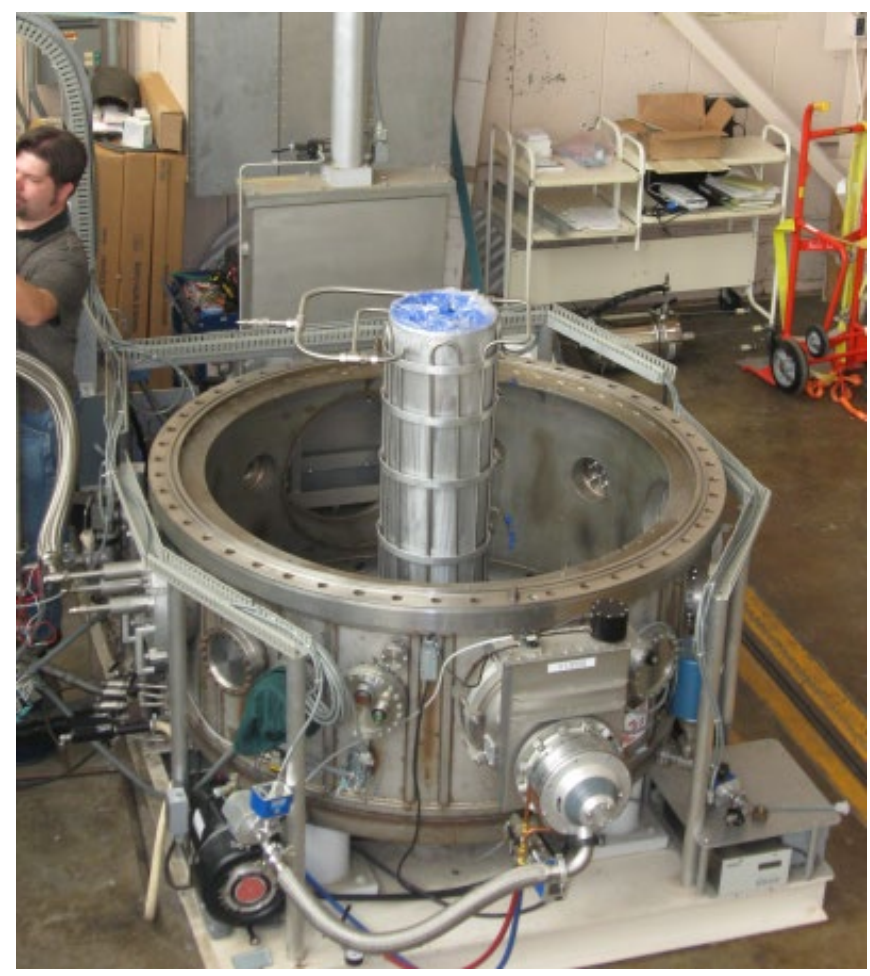

Figure 10.-The simulant bed in the VF13 chamber prior to vacuum testing.

\section{Vacuum Test}

A simulant bed has been prepared and is currently installed in the vacuum chamber (Figure 10). The final facility check-out tests are underway. The frozen simulant bed was transported to the vacuum chamber in under $1 \mathrm{hr}$, and is expected to take closer to 30 min now that transport procedures are known. The time from vacuum chamber installation until the start of liquid nitrogen flow is not yet known. Insulation may be added to the simulant bin to prevent thawing if this time is significant.

\section{Conclusions}

A simulant bed has been prepared to accommodate thermal vacuum testing of RESOLVE component hardware. This $0.278 \mathrm{~m}$ diameter, $1.2 \mathrm{~m}$ tall cylindrical simulant bin can accommodate drill subsystem test to full depth. Simulant preparation methods have been developed to obtain moisture levels expected on the lunar surface. Baseline compaction tests were performed at a range of moisture levels to determine maximum achievable bulk densities. This was done for GRC-3 and Chenobi lunar regolith simulants. Vibration compaction was the most viable method to accommodate a simulant bed of this size. It 
produced densities within the range of those measured on the lunar surface (returned core samples) and accommodated a larger diameter simulant bed that could support multiple drill holes. A layered fill procedure was used to compact the $1.2 \mathrm{~m}$ simulant bed. Vibration compaction on each successive layer resulted in a consistent bulk as layers were added. This suggests that the vibration did not undo the compaction of previous layers, so a layered vibrational compaction is viable. However, the bin had lower bulk densities than those achieved in a smaller vessel. Smaller layers, not to exceed the height of the ASTM vibration apparatus, will be used in future bed preparations to better correlate the densities.

During vacuum testing, the simulant bin will be wrapped in liquid nitrogen coolant tubes to achieve cryogenic temperatures expected on the lunar surface. However, an initial freeze of the simulant bed using a commercial upright freezer was used solidify the simulant bed prior to transport into the vacuum facility. Thermocouples embedded in the simulant indicated that the entire bed was frozen within $8 \mathrm{hr}$ inside the $-20{ }^{\circ} \mathrm{C}$ freezer. Once removed from the freezer, the most exposed locations of the simulant bed began to thaw in $2 \mathrm{hr}$. Transport of the simulant bed to the vacuum facility has been demonstrated in under $1 \mathrm{hr}$.

\section{References}

1. Kleinhenz, J.E. and Wilkinson, A., 2012, "ISRU Soil Mechanics Vacuum Facility: Soil Bin Preparation and Simulant Strength Characterization," $50^{\text {th }}$ Aerospace Sciences Meeting and Exhibit, American Institute for Aeronautics and Astronautics, AIAA-2012-0359.

2. LSB, G. H. Heiken, D. T. Vaniman, and B. M. French, Lunar Sourcebook: A User's Guide to the Moon, New York, Cambridge University Press, 1991.

3. Lakanen, G., Sigurdson, L., Boucher, D., and Timusk, M., 2012. "Development of an Intelligent Measure while Drilling System for Planetary Drills," $50^{\text {th }}$ Aerospace Sciences Meeting and Exhibit, American Institute for Aeronautics and Astronautics, AIAA-2012-0518.

4. ASTM Standard D698-07, "Standard Test Methods for Laboratory Compaction Characteristics of Soil Using Standard Effort (12 400ft-lbf/ $\left./ \mathrm{ft}^{3}\left(600 \mathrm{kN}-\mathrm{m} / \mathrm{m}^{3}\right)\right)$," ASTM International, West Conshohocken, PA.

5. ASTM Standard D4253-00, "Standard Test Methods for Maximum Index Density and Unit Weight of Soils Using a Vibratory Table," ASTM International, West Conshohocken, PA.

6. Colaprete, A., et al, 2010, "Detection of Water in the LCROSS Ejecta Plume," Science, 22, 463-468.

7. ASTM Standard D2216-05, "Standard Test Methods for Laboratory Determination of Water (moisture) Content of Soil and Rock by Mass," ASTM International, West Conshohocken, PA.

8. Gustafson, R., Grzesiak, B., Gertsch, L., and Rostami, J., 2009, "Low-Energy Planetary Excavator," NASA Phase 2 SBIR 2009 Final Report.

9. He, C., Zeng, X., and Wilkinson, A., "Geotechnical Properties of GRC3 Lunar Simulant," J. Aerosp. Eng., doi: 10.1061/(ASCE)AS.1943-5525.0000162.

10. Zeng, X., He, C., Oravec, H., Wilkinson, A., Agui, J., and Asnani, V. (2010). "Geotechnical Properties of JSC-1A Lunar Soil Simulant," J. Aerosp. Eng., 23(2), 111-116.

11. Zeng, X., He, C., and Wilkinson, A., 2010, "Geotechnical Properties of NT-LHT-2M Lunar Highland Simulant,” J. Aerosp. Eng., 23(4), 213-218. 


\begin{tabular}{|c|c|c|}
\hline \multicolumn{2}{|c|}{ REPORT DOCUMENTATION PAGE } & $\begin{array}{l}\text { Form Approved } \\
\text { OMB No. 0704-0188 }\end{array}$ \\
\hline \multicolumn{3}{|c|}{ 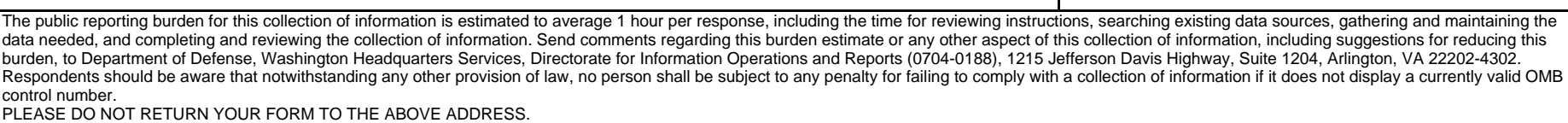 } \\
\hline $\begin{array}{l}\text { 1. REPORT DATE (DD-MM-YYYY) } \\
01-01-2013\end{array}$ & $\begin{array}{l}\text { 2. REPORT TYPE } \\
\text { Technical Memorandum }\end{array}$ & 3. DATES COVERED (From - To) \\
\hline \multirow{3}{*}{\multicolumn{2}{|c|}{$\begin{array}{l}\text { 4. TITLE AND SUBTITLE } \\
\text { Preparation of a Frozen Regolith Simulant Bed for ISRU Component Testing in a Vacuum } \\
\text { Chamber }\end{array}$}} & 5a. CONTRACT NUMBER \\
\hline & & 5b. GRANT NUMBER \\
\hline & & 5c. PROGRAM ELEMENT NUMBER \\
\hline \multirow{3}{*}{\multicolumn{2}{|c|}{$\begin{array}{l}\text { 6. AUTHOR(S) } \\
\text { Kleinhenz, Julie; Linne, Diane }\end{array}$}} & 5d. PROJECT NUMBER \\
\hline & & 5e. TASK NUMBER \\
\hline & & $\begin{array}{l}\text { 5f. WORK UNIT NUMBER } \\
\text { WBS 760231.05.03.03 }\end{array}$ \\
\hline \multicolumn{2}{|c|}{$\begin{array}{l}\text { 7. PERFORMING ORGANIZATION NAME(S) AND ADDRESS(ES) } \\
\text { National Aeronautics and Space Administration } \\
\text { John H. Glenn Research Center at Lewis Field } \\
\text { Cleveland, Ohio 44135-3191 }\end{array}$} & $\begin{array}{l}\text { 8. PERFORMING ORGANIZATION } \\
\text { REPORT NUMBER } \\
\text { E-18584 }\end{array}$ \\
\hline \multirow{2}{*}{\multicolumn{2}{|c|}{$\begin{array}{l}\text { 9. SPONSORING/MONITORING AGENCY NAME(S) AND ADDRESS(ES) } \\
\text { National Aeronautics and Space Administration } \\
\text { Washington, DC 20546-0001 }\end{array}$}} & $\begin{array}{l}\text { 10. SPONSORING/MONITOR'S } \\
\text { ACRONYM(S) } \\
\text { NASA }\end{array}$ \\
\hline & & $\begin{array}{l}\text { 11. SPONSORING/MONITORING } \\
\text { REPORT NUMBER } \\
\text { NASA/TM-2013-217833 }\end{array}$ \\
\hline \multicolumn{3}{|c|}{$\begin{array}{l}\text { 12. DISTRIBUTIONIAVAILABILITY STATEMENT } \\
\text { Unclassified-Unlimited } \\
\text { Subject Category: } 91 \\
\text { Available electronically at http://Www.sti.nasa.gov } \\
\text { This publication is available from the NASA Center for AeroSpace Information, 443-757-5802 }\end{array}$} \\
\hline
\end{tabular}

\section{SUPPLEMENTARY NOTES}

\section{ABSTRACT}

In-Situ Resource Utilization (ISRU) systems and components have undergone extensive laboratory and field tests to expose hardware to relevant soil environments. The next step is to combine these soil environments with relevant pressure and temperature conditions. Previous testing has demonstrated how to incorporate large bins of unconsolidated lunar regolith into sufficiently sized vacuum chambers. In order to create appropriate depth dependent soil characteristics that are needed to test drilling operations for the lunar surface, the regolith simulant bed must by properly compacted and frozen. While small cryogenic simulant beds have been created for laboratory tests, this scale effort will allow testing of a full $1 \mathrm{~m}$ drill which has been developed for a potential lunar prospector mission. Compacted bulk densities were measured at various moisture contents for GRC-3 and Chenobi regolith simulants. Vibrational compaction methods were compared with the previously used hammer compaction, or "Proctor", method. All testing was done per ASTM standard methods. A full $6.13 \mathrm{~m}^{3}$ simulant bed with 6 percent moisture by weight was prepared, compacted in layers, and frozen in a commercial freezer. Temperature and desiccation data was collected to determine logistics for preparation and transport of the simulant bed for thermal vacuum testing. Once in the vacuum facility, the simulant bed will be cryogenically frozen with liquid nitrogen. These cryogenic vacuum tests are underway, but results will not be included in this manuscript.

\section{SUBJECT TERMS}

Lunar regolith; Granular materials; In situ resource utilization

\begin{tabular}{|c|c|c|c|c|c|}
\hline \multicolumn{3}{|c|}{ 16. SECURITY CLASSIFICATION OF: } & \multirow{2}{*}{$\begin{array}{l}\text { 17. LIMITATION OF } \\
\text { ABSTRACT } \\
\text { UU }\end{array}$} & \multirow{2}{*}{$\begin{array}{l}\text { 18. NUMBER } \\
\text { OF } \\
\text { PAGES } \\
20\end{array}$} & \multirow{2}{*}{$\begin{array}{l}\text { 19a. NAME OF RESPONSIBLE PERSON } \\
\text { STI Help Desk (email:help@sti.nasa.gov) } \\
\text { 19b. TELEPHONE NUMBER (include area code) } \\
\text { 443-757-5802 }\end{array}$} \\
\hline $\begin{array}{l}\text { a. REPORT } \\
U\end{array}$ & $\begin{array}{l}\text { b. ABSTRACT } \\
U\end{array}$ & $\begin{array}{l}\text { c. THIS } \\
\text { PAGE } \\
\text { U }\end{array}$ & & & \\
\hline
\end{tabular}



